\title{
(6) OPEN ACCESS \\ Long-term safety of rituximab in rheumatoid arthritis: 9.5-year follow-up of the global clinical trial programme with a focus on adverse events of interest in RA patients
}

\author{
Ronald F van Vollenhoven, ${ }^{1}$ Paul Emery, ${ }^{2}$ Clifton 0 Bingham III, ${ }^{3}$ Edward C Keystone, ${ }^{4}$ \\ Roy M Fleischmann, ${ }^{5}$ Daniel E Furst, ${ }^{6}$ Nicola Tyson, ${ }^{7}$ Neil Collinson, ${ }^{7}$ Patricia B Lehane ${ }^{7}$
}

\begin{abstract}
Handling editor Tore K Kvien
- Additional data are published online only. To view these files please visit the journal online (http://dx.doi.org/ 10.1136/annrheumdis-2012201956).

${ }^{1}$ Unit for Clinical Therapy Research, The Karolinska Institute, Stockholm, Sweden ${ }^{2}$ Section of Musculoskeletal Disease, Leeds

Musculoskeletal Biomedical Research Unit, Leeds Teaching Hospitals Trust, University of

Leeds, Leeds, UK

${ }^{3}$ Department of Rheumatology, Johns Hopkins University, Baltimore, Maryland, USA ${ }^{4}$ Department of Rheumatology, Mount Sinai Hospital,

University of Toronto, Toronto, Ontario, Canada

${ }^{5}$ Department of Rheumatology, University of Texas

Southwestern Medical Center at Dallas, Dallas, Texas, USA

${ }^{6}$ Department of Rheumatology, UCLA, Los Angeles, California, USA

${ }^{7}$ Roche Products Ltd, Welwyn Garden City, UK
\end{abstract}

\section{Correspondence to} Dr Ronald F van Vollenhoven, Unit for Clinical Therapy Research, Inflammatory Diseases, The Karolinska University Hospital, D1:00, 17176, Stockholm, Sweden; ronald.van.vollenhoven@ki.se

Accepted 11 September 2012 Published Online First 7 November 2012

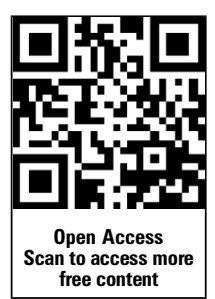

\section{ABSTRACT}

Objectives Evaluation of long-term safety of rituximab in rheumatoid arthritis (RA).

Methods Pooled observed case analysis of data from patients with moderate-to-severe, active RA treated with rituximab in a global clinical trial programme.

Results As of September 2010, 3194 patients had received up to 17 rituximab courses over 9.5 years (11 962 patient-years). Of these, 627 had $>5$ years' follow-up (4418 patient-years). A pooled placebo population $(n=818)$ (placebo + methotrexate (MTX)) was also analysed. Serious adverse event and infection rates generally remained stable over time and multiple courses. The overall serious infection event (SIE) rate was 3.94/ 100 patient-years (3.26/100 patient-years in patients observed for $>5$ years) and was comparable with placebo + MTX (3.79/100 patient-years). Serious opportunistic infections were rare. Overall, 22.4\% $(n=717)$ of rituximab-treated patients developed low immunoglobulin (lg) M and 3.5\% ( $n=112)$ low lgG levels for $\geq 4$ months after $\geq 1$ course. SIE rates were similar before and during/after development of low lg levels; however, in patients with low lgG, rates were higher than in patients who never developed low lgG. Rates of myocardial infarction and stroke were consistent with rates in the general RA population. No increased risk of malignancy over time was observed.

Conclusions This analysis demonstrates that rituximab remains generally well tolerated over time and multiple courses, with a safety profile consistent with published data and clinical trial experience. Overall, the findings indicate that there was no evidence of an increased safety risk or increased reporting rates of any types of adverse events with prolonged exposure to rituximab during the 9.5 years of observation.

\section{INTRODUCTION}

Rheumatoid arthritis (RA) is associated with an increased risk of serious infection events (SIE), ${ }^{1}$ lymphomas ${ }^{2}$ and with increased death rates due to cardiovascular disease. ${ }^{3}$ Biological disease-modifying antirheumatic drugs (DMARDs), including tumour necrosis factor (TNF) inhibitors, may further increase the risk of SIE and malignancies. ${ }^{1}$ 4-7 Continual monitoring of long-term safety of patients receiving biological therapies is therefore of paramount importance.
B cell-targeted therapy using the anti-CD20 monoclonal antibody rituximab is an effective treatment for RA. In combination with methotrexate (MTX), rituximab improves the signs and symptoms of RA and slows joint damage progression. ${ }^{8-15}$ Data from eight randomised, placebocontrolled trials in patients with moderately to severely active RA demonstrated that the overall rates of adverse events (AEs) and serious AEs (SAEs), including SIE, were similar to those observed with placebo + MTX. ${ }^{8-11}{ }^{13-16}$ Long-term follow-up of patients in these trials indicated that rituximab remained well tolerated over time and multiple courses. ${ }^{17}$ These data are encouraging; however, the safety of repeated peripheral B cell depletion, in particular regarding the potential cumulative risk of SIE and malignancies, remains to be fully established.

This analysis further evaluated the long-term safety of rituximab to determine the consequences of repeat treatment with a peripheral B cell depleting therapy over many years. We focused on specific AEs that could potentially be attributed to the immunological effects of peripheral $B$ cell depletion as well as on AEs of special interest in RA patients. The current analysis involves a larger number of patients than previously reported (>3000 patients with nearly 12000 patient-years of observation), including a substantial number of patients treated for $>5$ years.

\section{MATERIALS AND METHODS \\ Studies and analysis}

This was a pooled observed case analysis of safety data of patients with moderate-to-severe, active RA treated with rituximab in combination with MTX in a global clinical trial programme (eight randomised trials and two long-term, open-label extensions). Trials included in the 'All Exposure' analysis are shown in online supplementary figure S1. Eligibility criteria and study designs have been published previously. ${ }^{8-16}$ Each rituximab course consisted of intravenous infusions of either $2 \times 1000 \mathrm{mg}$ or $2 \times 500 \mathrm{mg}$ given 2 weeks apart. Prior to each infusion, all patients received intravenous methylprednisolone $100 \mathrm{mg}$; most patients also received acetaminophen and an antihistamine. Repeat treatment was based on the physician's 
decision of clinical need and included evidence of active disease (either swollen joint count and tender joint count $\geq 8$ or disease activity score in 28 joints-erythrocyte sedimentation rate 22.6). Patients received concomitant MTX $10-25 \mathrm{mg} /$ week at a stable dose. Background oral corticosteroids and non-steroidal anti-inflammatory drugs were also permitted.

\section{Safety assessments}

Safety assessments were conducted as previously reported. ${ }^{17}$ Patients were followed for the study period and for 1 year after completion or withdrawal. Patients who remained B cell depleted after this time were followed until peripheral B cells returned to lower limit of normal or baseline, whichever occurred earlier. All AEs were captured for the first month in safety follow-up periods, after which time only SAEs and all infection events were collected. Original reported terms were assigned preferred terms using the Medical Dictionary for Regulatory Activities (MedDRA), V.13.1. All potential malignant events (identified by the wide, malignant or unspecified reviewed by the Sponsor to confirm actual malignancies (evidenced by reported histology and information from investigational sites). AEs classified as infections included all preferred terms of the 'Infections and Infestations' System Organ Class (SOC) and an additional nine terms from other MedDRA SOCs that could be considered to be due to underlying infection. SIE were defined as infections reported as an SAE or which required treatment with intravenous anti-infectives.

\section{Data analysis}

The analysis populations consisted of the All Exposure population (all patients exposed to at least one or part of one rituximab infusion, regardless of dose), the 5-year population (a subset of the All Exposure population with >5years' follow-up) and the pooled placebo population (all patients who received placebo during placebo-controlled study periods and patients who initially received placebo but were subsequently treated with rituximab (placebo-switch patients)) (placebo + MTX). For placebo-switch patients, safety data were included in the placebo+MTX population up to the time of first rituximab exposure; thereafter, the data were included in the rituximab-treated population. The All Exposure population included patients who had never received prior MTX treatment, DMARD-inadequate responders and inadequate responders to prior TNF inhibitors and/or other biologicals (primarily anakinra). TNF inhibitor/biological-inadequate responders comprised $40 \%$ of the All Exposure population.

\section{RESULTS \\ Duration of exposure}

As of September 2010, 3194 patients had been treated with up to 17 courses of rituximab for up to 9.5 years, providing 11962 patient-years of observation in the All Exposure population. Of patients exposed to rituximab, 1935 had been followed for $>3$ years and 627 for $>5$ years. All patients received at least one treatment course; 2428, 1739, 1451, 1154 and 849 patients received $\geq 2, \geq 3, \geq 4, \geq 5$ and $\geq 6$ courses, respectively (see online supplementary figure S2). The greatest number of withdrawals occurred following the first two courses (962 patients (30\%)), principally for non-safety reasons and because two studies limited patients to receive one or two courses per protocol. Across the trials, there was a normal expected drop-out rate $(1 \%-13 \%)$ for subsequent courses. Overall, withdrawals due to AEs were infrequent (190 patients). Most withdrawals were tumours standard MedDRA query (SMQ)), were medically

attributed to 'other' reasons which included insufficient therapeutic response, failure to return, violation of selection criteria at entry, other protocol violation, refused treatment/did not cooperate, withdrew consent, administrative/other (including patient entry to extension protocols), lost to follow-up, physician's decision to withdraw and pregnancy. Of those patients who remained in the study, there were very little data that were not recorded and of the data that were missing, they were missing at random.

The placebo+MTX population included 818 patients (1107 patient-years) with a substantially shorter mean duration of follow-up ( $>50 \%$ withdrew from placebo follow-up by 1 year and $93 \%$ by 3 years). Differences in patient numbers and duration of follow-up should be considered during interpretation of data.

\section{Baseline demographics and disease characteristics}

Most patients were female subjects with a mean age of approximately 51 years. Patients had received an average of two previous DMARDs (excluding MTX). Baseline demographics and disease characteristics were comparable across the analysis populations (table 1) except for a longer mean RA disease duration and a greater number of previous DMARDs in the 5-year population (table 1)

\section{AEs and SAEs}

Overall rates of AEs and SAEs were comparable in the All Exposure (including the 5-year population) and placebo+MTX populations (table 2). AE rates were the highest during the 6 months after first rituximab exposure (owing in part to infusion-related reactions (IRRs)) and generally remained stable thereafter, irrespective of number of courses received (data not shown). The most common AE was IRR; most were common terminology criteria (CTC) grade 1 or 2 and were rarely serious, with the majority occurring at first infusion of the first course (734/3194 patients; 23.0\%). The frequency, type and intensity

Table 1 Patient characteristics at baseline*

\begin{tabular}{|c|c|c|c|}
\hline & $\begin{array}{l}\text { Rituximab+ } \\
\text { MTX } \\
\text { All Exposure } \\
(\mathrm{n}=3194)\end{array}$ & $\begin{array}{l}\text { Rituximab }+ \\
\text { MTX } \\
>5 \text { years } \\
(n=627)\end{array}$ & $\begin{array}{l}\text { Placebo+MTX } \\
(n=818)\end{array}$ \\
\hline Age (years) & 51.5 & 51.8 & 51.0 \\
\hline Female (\%) & 80.8 & 80.1 & 80.4 \\
\hline Disease duration (years) & 8.3 & 11.1 & 7.1 \\
\hline Swollen joint count & 20.0 & 21.5 & 17.7 \\
\hline Tender joint count & 31.1 & 32.4 & 28.6 \\
\hline $\mathrm{CRP}(\mathrm{mg} / \mathrm{dl})$ & 2.83 & 3.37 & 2.83 \\
\hline $\mathrm{ESR}(\mathrm{mm} / \mathrm{h})$ & 47.1 & 46.1 & 45.2 \\
\hline DAS28-ESR & 6.64 & 6.78 & 6.32 \\
\hline RF-positive (\%) & 77.6 & 85.3 & 81.3 \\
\hline $\begin{array}{l}\text { Number of previous } \\
\text { biologicals or DMARDs } \dagger\end{array}$ & 2.2 & 3.1 & 1.9 \\
\hline $\begin{array}{l}\text { Number of previous } \\
\text { biologicals }\end{array}$ & 0.7 & 0.9 & 0.5 \\
\hline $\begin{array}{l}\text { Baseline concomitant } \\
\text { corticosteroids (\%) }\end{array}$ & 52.4 & 55.0 & 53.2 \\
\hline \multicolumn{4}{|c|}{$\begin{array}{l}\text { *Baseline characteristics were the observed mean values of the original baseline, } \\
\text { where original baseline was the screening or baseline visit in the patient's original } \\
\text { study. } \\
\text { tExcluding MTX. } \\
\text { CRP, C reactive protein; DAS28, disease activity score in } 28 \text { joints; } \\
\text { DMARD, disease-modifying antirheumatic drug; ESR, erythrocyte sedimentation } \\
\text { rate; MTX, methotrexate; RF, rheumatoid factor. }\end{array}$} \\
\hline
\end{tabular}


Table 2 Summary of adverse events/100 pt-years

\begin{tabular}{|c|c|c|c|}
\hline & $\begin{array}{l}\text { Rituximab+MTX } \\
\text { All Exposure }(n=3194)\end{array}$ & $\begin{array}{l}\text { Rituximab +MTX } \\
>5 \text { years }(n=627)\end{array}$ & Placebo + MTX $(n=818)$ \\
\hline Exposure (pt-years) & 11962 & 4418 & 1107 \\
\hline AEs/100 pt-years (95\% Cl) & $263.10(260.21$ to 266.02$)$ & 254.12 (249.46 to 258.86$)$ & 315.43 (305.14 to 326.06$)$ \\
\hline SAEs/100 pt-years (95\% Cl) & 14.40 (13.73 to 15.09$)$ & $14.30(13.23$ to 15.46$)$ & 13.82 (11.79 to 16.19$)$ \\
\hline Infections/100 pt-years (95\% Cl) & 81.64 (80.04 to 83.27$)$ & 75.41 (72.89 to 78.02$)$ & 90.39 (84.96 to 96.17$)$ \\
\hline SIEs/100 pt-years (95\% CI) & 3.94 (3.60 to 4.31$)$ & 3.26 (2.77 to 3.84$)$ & $3.79(2.80$ to 5.13$)$ \\
\hline
\end{tabular}

$\mathrm{AE}$, adverse event; MTX, methotrexate; pt-year, patient-year; SAE, serious adverse event; SIE, serious infection event.

of IRRs and other AEs were consistent with that previously reported. ${ }^{17}$ Serious IRRs were rare and included anaphylactic or anaphylactoid reactions, drug hypersensitivity and angioedema. Overall, 19 events were reported in $17(0.5 \%)$ patients, of which 10 occurred during the first infusion of Course 1. No serious IRRs occurred beyond Course 6. SAEs most commonly observed in the All Exposure population were RA exacerbation $(\mathrm{n}=76 ; 2 \%)$, pneumonia $(\mathrm{n}=59 ; 2 \%)$, fall $(\mathrm{n}=55 ; 2 \%)$ and osteoarthritis $(n=49 ; 2 \%)$. Withdrawals due to AEs were infrequent $(n=190 ; 6 \%)$, the most common causes being RA disease activity $(n=44 ; 1.4 \%)$, neoplasms $(n=41 ; 1.3 \%)$, IRRs $(n=40$; $1.3 \%$ ), infections and infestations $(n=29 ; 0.9 \%)$, respiratory disorders $(n=16 ; 0.5 \%)$ and cardiac disorders $(n=9 ; 0.3 \%)$.

\section{Deaths}

There were 61 deaths in the All Exposure (0.51/100 patientyears $(95 \%$ CI 0.40 to 0.66$)$ ) and seven in the placebo+MTX population (0.63/100 patient-years ( $95 \%$ CI 0.30 to 1.33$)$ ). Causes of death varied and were typical for a patient population with active RA. In rituximab-treated patients, primary causes of death included infection $(n=14)$, cardiovascular events $(n=13)$, malignancies $(n=11)$ and respiratory disorders $(\mathrm{n}=5)$. In placebo patients, deaths were attributed to cardiovascular events $(n=3)$, infection $(n=2)$ and gastrointestinal disorders $(n=2)$. Incidence of death did not appear to increase with cumulative exposure to rituximab and there were no infusionrelated deaths. Death rates were consistent with the previous analysis ${ }^{17}$ and with the rate expected in an age- and sexmatched general US population. ${ }^{18}$

\section{Infections}

SIE rates in both the All Exposure and 5-year populations were comparable with that observed in the placebo+MTX population (table 2). Infection rates generally remained stable over time (figure $1 \mathrm{~A}, \mathrm{~B}$ ) and multiple treatment courses. The most commonly reported infections ( $>5 \%$ patients) in rituximab patients were upper respiratory tract infections, nasopharyngitis, urinary tract infections, bronchitis, sinusitis, diarrhoea, influenza and gastroenteritis, while the most frequent SIE was lower respiratory tract infection, predominantly pneumonia $(2 \%)$. There was no increase in SIE rates among patients who received subsequent biological therapy (including TNF inhibitors) following rituximab treatment (table 3). SIE rates were also similar (4.25 (95\% CI 1.91 to 9.4$)$ vs 4.21 (95\% CI 2.33 to 7.60$)$ patient-years) in patients who received their biologic $<6$ months $(n=90)$ and $\geq 6$ months $(n=224)$ after last rituximab dose. A proportion of these patients (194/314, 62\%) had $\mathrm{CD} 19+$ cell counts $<20$ cells/ $\mu$ l prior to their subsequent biologic; the SIE rate post-biologic in these patients was 5.35/100 patient-years ( $95 \%$ CI 3.28 to 8.74 ).

\section{Infections of special interest}

Serious opportunistic infections were rare, with seven events reported in the All Exposure population (two cases of atypical pneumonia (no organisms isolated) and one case each of Candida septicaemia, pharyngeal abscess (organism unspecified), Scedosporium lung infection, Pneumocystis jirovecii pneumonia and progressive multifocal leucoencephalopathy (PML) with fatal outcome ${ }^{19}$ ), and one event in the placebo + MTX population (P jirovecii pneumonia), corresponding to rates of $0.06 / 100$ patient-years and $0.09 / 100$ patient-years, respectively. Two cases of pulmonary tuberculosis (TB), both treated with anti-TB medication, occurred in the All Exposure population; no cases of extra-pulmonary TB, atypical mycobacterial infection or multidrug-resistant TB were observed. No cases of hepatitis $B$ reactivation occurred in the All Exposure population. A single case of de novo hepatitis B infection occurred in a 59-year-old female patient following a dental procedure, as reported previously. ${ }^{11}$ In the All Exposure population, 108 AEs of herpes zoster were reported in 100 patients, including two cases of ophthalmic herpes zoster and five SAEs. In the placebo+MTX population, 13 events of herpes zoster were reported. Among patients with herpes zoster, $73 \%$ were receiving concomitant oral corticosteroids that were ongoing prior to or that had started on the same day as the AE. Rates of herpes zoster (9.0/1000 patient-years) were comparable with the placebo+MTX (11.7/1000 patient-years) and general RA populations $\left(11.5 / 1000\right.$ patient-years ${ }^{20}{ }^{2}$

\section{Infection risk in patients with low Ig levels}

Immunoglobulins (Igs) were generally measured every 8-16 weeks. Analysis was performed to assess the rates of all infections and SIE in patients before and after a low (<lower limit of normal) IgG or IgM level for at least a 4-month period (or two consecutive clinical study visits) following treatment with rituximab. Low Ig levels at baseline screening (IgG $<5.65$ and IgM $<0.55 \mathrm{mg} / \mathrm{ml}$ ) were exclusion criteria for trial entry. Overall, $22.4 \%(n=717)$ of rituximab-treated patients developed low $\operatorname{IgM}$ and a smaller proportion developed low $\operatorname{IgG}(3.5 \%$; $n=112)$ or low IgA $(1.1 \% ; n=36)$ for $\geq 4$ months after $\geq 1$ course. All patients had measurable Ig levels, although analysis of IgA was limited by the small sample size. No increases in overall infection rates were observed in patients during/after development of low IgM or IgG (table 4). For IgG, SIE rates were similar before and during/after low IgG, but both rates were significantly higher than in patients who never developed low IgG. At baseline these patients were on average older, had longer disease duration, lower mean CD19+count, lower mean IgG levels ( 8.4 vs $13.2 \mathrm{mg} / \mathrm{ml}$ ) and had received more nonbiological DMARDs. Baseline oral steroid use was similar across subgroups. For IgM, SIE rates were not significantly higher during/after low IgM versus before low IgM, and were similar to rates in patients who never developed low IgM. In patients 


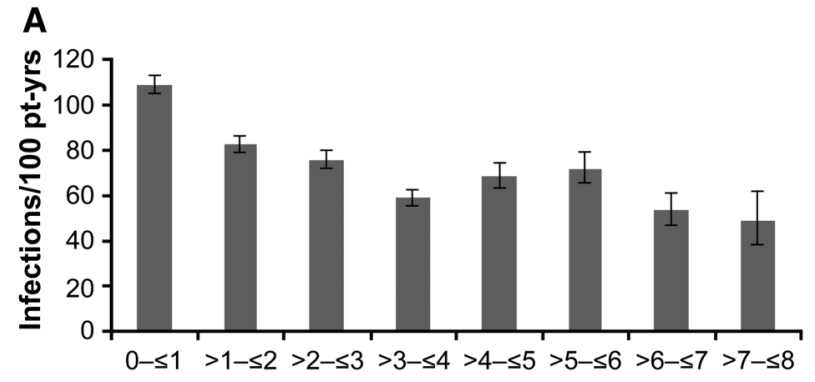

$\begin{array}{llllllll}\text { Total pt-yrs } 3111 & 2751 & 2193 & 1689 & 935 & 579 & 444 & 137\end{array}$ exposure

Time (year)

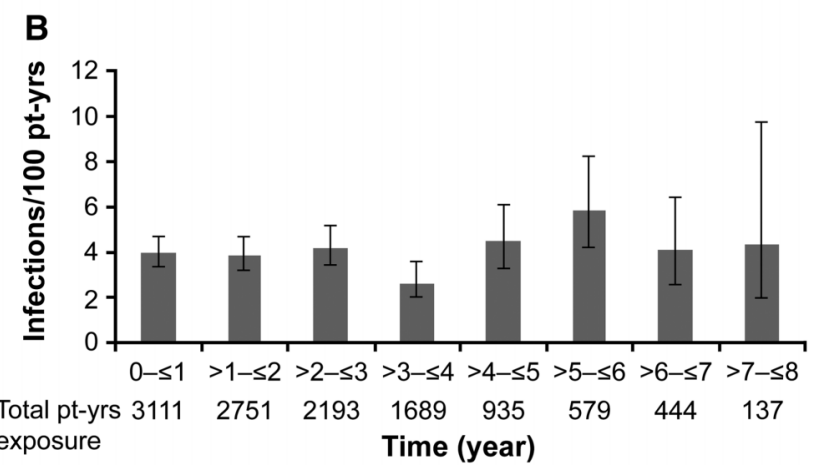

Figure 1 (A) Infection rates and (B) serious infection rates over time -All Exposure population (including subgroup with follow-up of $>5$ years). Bars indicate (A) infections or (B) serious infection events/ 100 patient-years. Error bars indicate $95 \%$ Cls. pt-yrs, patient years.

with low IgM/IgG, the SIE profile was consistent with the All Exposure population. Analysis of SIE onset relative to the timing of low Ig was limited due to discrete protocol-defined time points for Ig assessments; in addition, low patient numbers in some subgroups and the lack of a placebo comparator further restricted Ig analysis.

\section{Cardiac events}

Myocardial infarction (MI) was the most common serious cardiac event in the All Exposure population (49 events in 42 patients; $1.3 \%$ ). The event rate was $0.41 / 100$ patient-years ( $95 \%$ CI 0.31 to 0.54 ) versus $0.27 / 100$ patient-years $(95 \% \mathrm{CI}$ 0.09 to 0.84$)$ in the placebo+MTX population. As previously reported, ${ }^{17}$ most patients experiencing MI had at least one conventional risk factor. The rate of stroke in the All Exposure population was $0.19 / 100$ patient-years ( $95 \%$ CI 0.13 to 0.29 ) versus $0.18 / 100$ patient-years $(95 \%$ CI 0.05 to 0.72 ) in the placebo+MTX population.

\section{Malignancies}

The rate of all malignant and unspecified tumours and nonmelanoma skin cancers (NMSC) in the All Exposure population was $1.32 / 100$ patient-years $(95 \%$ CI 1.13 to 1.54$)$ versus
$1.17 / 100$ patient-years (95\% CI 0.68 to 2.02 ) in the placebo+ MTX population. The rate of serious malignancies (SAEs as reported by the investigator) was $0.74 / 100$ and $0.81 / 100$ patient-years in the All Exposure and placebo+MTX populations, respectively. NMSC represented approximately a third of reported events; however, as NMSC is not generally reported to cancer surveillance databases these events were excluded in the evaluation of overall malignancy rate. There were 83 confirmed malignancies identified by the Sponsor medical review (from a total of 158 events captured by the MedDRA SMQ) in the All Exposure population, excluding duplications, NMSC and nonmalignant (benign) events, providing a malignancy incidence rate (any site) of $0.69 / 100$ patient-years (95\% CI 0.56 to 0.86 ). For solid tumours, the most frequently reported malignancy was breast cancer (table 5). Rituximab-treated patients did not have an increased rate of any malignancy compared with other patients with RA in observational studies. ${ }^{21}{ }^{22}$ There was no evidence of an increased risk of malignancy with cumulative exposure to rituximab as malignancy rates did not increase with number of courses or over time. Furthermore, no increased risk of malignancy for rituximab-treated patients was indicated when comparing the age- and sex-matched standardised incidence ratios for all confirmed malignancies and breast cancer with the general US population Surveillance Epidemiology and End Results (SEER) database, ${ }^{23}$ and with published data in adults with $\mathrm{RA}^{24}$ (table 5).

\section{DISCUSSION}

This report presents safety data from the global rituximab RA clinical trial programme in 3194 patients with 11962 patientyears of follow-up. Compared with a previous analysis, ${ }^{17}$ this represents almost 7000 additional patient-years of follow-up with $20 \%$ more patients, and includes a placebo + MTX population for comparison. The inclusion of 627 patients with $>5$ years of observation, with some patients having received up to 17 rituximab courses over 9.5 years of observation, affords a high level of confidence in the data and increases the probability of detecting common and infrequent safety risks compared with previous studies. ${ }^{12} 17$

$\mathrm{AE}$ and $\mathrm{SAE}$ rates generally remained stable over time and over multiple courses, and the most common SAEs in the All Exposure population were typical of biological-treated RA patients. ${ }^{25} 26$ The overall SIE rate (3.94/100 patient-years) was within the range reported (3.0 to 5.2/100 patient-years) for long-term follow-up with other RA biologics. ${ }^{6}$ 25-27 These observations are consistent with controlled rituximab trials ${ }^{10} 11$ and a meta-analysis of randomised controlled trials that did not identify a significant increase in SIE risk during rituximab treatment. ${ }^{28}$ Opportunistic infections were rare. No further cases of PML in the RA clinical trial programme have been reported other than the single case previously described. ${ }^{19}$ The occurrence of confirmed PML from spontaneous reporting and clinical trial sources remains very rare (six confirmed cases in

Table 3 SIE rate before and after treatment with subsequent biologics, including TNF inhibitors

\begin{tabular}{|c|c|c|c|c|}
\hline & \multicolumn{2}{|c|}{$\begin{array}{l}\text { All patients receiving any biologic following rituximab } \\
\text { treatment }(n=314)\end{array}$} & \multicolumn{2}{|c|}{$\begin{array}{l}\text { Subset of patients receiving a TNF inhibitor following } \\
\text { rituximab treatment }(n=258)\end{array}$} \\
\hline & Before other biologic & After other biologic & Before TNF inhibitor & After TNF inhibitor \\
\hline SIEs, n & 26 & 17 & 21 & 13 \\
\hline SIEs/100 pt-years (95\% CI) & 5.16 (3.51 to 7.58$)$ & 4.22 (2.63 to 6.79$)$ & 5.27 (3.44 to 8.09$)$ & 3.94 (2.29 to 6.79$)$ \\
\hline
\end{tabular}

pt-year, patient-year; SIE, serious infection event; TNF, tumour necrosis factor. 
Table 4 Summary of infections in patients with $\lg \mathrm{G} / \mathrm{lgM}<\mathrm{LLN}$ for at least 4 months

\begin{tabular}{|c|c|c|c|c|c|c|}
\hline & \multicolumn{3}{|c|}{ Patients with $\lg G<L L N^{*}$} & \multicolumn{3}{|c|}{ Patients with $\lg M<<L^{*}{ }^{*}$} \\
\hline & $\begin{array}{l}\text { Before <LLN } \\
(n=112)\end{array}$ & $\begin{array}{l}\text { During/after <LLN } \\
(n=112)\end{array}$ & $\begin{array}{l}\text { Never <LLN } \\
(n=3082)\end{array}$ & $\begin{array}{l}\text { Before <LLN } \\
(n=717)\end{array}$ & $\begin{array}{l}\text { During/after <LLN } \\
(\mathbf{n}=\mathbf{7 1 7})\end{array}$ & $\begin{array}{l}\text { Never }<\text { LLN } \\
(n=2477)\end{array}$ \\
\hline Infections, n & 325 & 262 & 9179 & 1264 & 1699 & 6803 \\
\hline $\begin{array}{l}\text { Infections/100 pt-years } \\
(95 \% \mathrm{CI})\end{array}$ & 146 (131 to 162$)$ & 85 (76 to 96$)$ & 80 (79 to 82 ) & $108(10$ to 114$)$ & 82 (78 to 86$)$ & 78 (76 to 80$)$ \\
\hline
\end{tabular}

*Below LLN for $\geq 4$ months. LLN of Ig levels varied according to the central laboratory used and depended on various patient-related factors (such as age and gender). 'Before' refers to patient follow-up after rituximab treatment but prior to Ig levels falling below LLN. 'During/after' refers to follow-up once Ig levels have fallen below LLN. Ig, immunoglobulin; LLN, lower limit of normal; pt-year, patient-year; SIE, serious infection event.

estimated 188228 RA patients treated with rituximab, as of November 2011 (Roche data on file)). Herpes zoster rates were consistent with placebo+MTX and general RA populations. ${ }^{20}$

Decreases in Ig levels were observed in some patients following rituximab treatment although the clinical consequences of this are unclear. Analysis of registry data has previously shown that a low IgG level $(<6 \mathrm{~g} / \mathrm{l})$ before rituximab treatment was associated with an increased risk of SIE. ${ }^{29}$ Low baseline IgG was an exclusion criterion in the RA clinical trials and therefore this observation could not be confirmed or refuted. Following rituximab treatment, low Ig concentrations (particularly IgM) were observed in some patients. Patients with low IgM had no increased risk of infections or SIE. It is well established that reduced IgG levels are inherently associated with an increased risk of infections. ${ }^{30}$ Nevertheless, for the small subgroup of patients with low IgG, a higher SIE rate was seen both before and after the development of low IgG compared with patients who never developed low IgG, suggesting that these patients had a higher inherent risk of developing SIE, possibly associated with demographical and/or clinical characteristics rather than with low IgG itself. Thus, for both Ig classes, SIE rates were similar before and after development of low levels. Limitations of the Ig analysis included low patient numbers in the IgG subgroup, lack of a placebo comparator and lack of correlation (due to protocol-defined Ig measurements) between SIE onset and recording of low Ig levels.

RA patients are known to be at an increased risk of cardiovascular disease. ${ }^{31}$ Consistent with this, MI was the most frequent cardiac $\mathrm{AE}$ reported in rituximab-treated patients. Most patients experiencing MI had at least one conventional risk factor, although it has been reported that cardiovascular morbidity in RA patients cannot be fully explained by such risk factors and that RA-associated inflammation and underlying disease may also be a contributing factor. ${ }^{32}$ The MI rate reported for rituximab-treated patients is consistent with epidemiological data from a general RA population receiving TNF inhibitors or DMARDs (0.48 to $0.59 / 100$ patient-years) ${ }^{31} 33$ and there was no evidence to suggest an increased risk of MI associated with rituximab treatment. The rate of stroke was also consistent with published data in RA patients. ${ }^{31} 34$

As might be expected in a predominantly female study population with a mean age of 51 years, the most common solid tumour was breast cancer. Age- and sex-matched standardised incidence ratios for all confirmed malignancies and breast cancer did not indicate an increased risk of malignancy for rituximab-treated RA patients compared with the general US population (SEER database) ${ }^{23}$ and with published data in adults with RA. ${ }^{21} 222435$

The rate of fatal AEs remained consistent through the observation period and there was no evidence of an increased rate of any type of fatal event with prolonged rituximab exposure. The overall death rate observed in the rituximab RA clinical development programme was within the expected range for patients receiving a biological therapy ${ }^{36}$ and leading causes of death were also consistent with those expected in such a population.

The analysis has potential limitations. Data were pooled from diverse studies in which rituximab doses, retreatment regimens and prior or active disease status could differ. Notably,

Table 5 Rate of malignancy and standardised incidence ratio for malignancy in the rituximab All Exposure population and published data in adults with RA

\begin{tabular}{|c|c|c|}
\hline & Any site* & Breast $†$ \\
\hline All Exposure population $(95 \% \mathrm{Cl})$ & $0.69(0.55$ to 0.86$)$ & $0.12(0.06$ to 0.20$)$ \\
\hline Danish Cancer Registry $\ddagger$ & 1.17 & 0.13 \\
\hline National Databank for Rheumatic Diseases§ & 1.30 & 0.21 \\
\hline \multicolumn{3}{|l|}{ Standardised incidence ratio } \\
\hline \multicolumn{3}{|c|}{$\begin{array}{l}\text { *Excluding non-melanoma skin cancer and non-malignant events. } \\
\text { †Only female patients. } \\
\text { ¥Mellemkjaer et al. } .^{21} \\
\text { §Wolfe and Michaud. }{ }^{22} \\
\text { TSurveillance Epidemiology and End Results database }{ }^{23} \text { was used to obtain age- and sex-specific incidence ratio of malignancies for the US general population for standardised } \\
\text { incidence ratio calculations (data were accessed in February 2011). } \\
{ }^{* *} \text { Smitten et al. }{ }^{24} \\
\text { pt-year, patient year; RA, rheumatoid arthritis. }\end{array}$} \\
\hline
\end{tabular}


two of the studies limited patients to receive one or two rituximab courses, thus reducing the overall number of patients receiving higher numbers of courses. In addition, clinical trial data are heavily influenced by the fact that patients are selected at baseline to exclude significant comorbidities, and only those who did well clinically remained in the study. Finally, the mean observation period of patients in the placebo+MTX population was considerably shorter than that of patients in the All Exposure population, and this should be borne in mind when making comparisons. Notwithstanding these limitations, the key strength of this analysis is the long observation and follow-up period in a population of patients with active RA, which included frequent assessments, including those performed after study withdrawal or completion (minimum 1 year) and during extended periods of peripheral B cell depletion. In addition, the overall number of patients withdrawing due to AEs was low ( $6 \%$ in total).

In summary, evidence from the RA clinical trial data of up to 9.5 years of follow-up of 3194 patients treated with rituximab, including a substantial number of patients with $>5$ years' observation, revealed no new safety signals. Rituximab has remained generally well tolerated over time and over multiple courses, with a safety profile consistent with published data of patients with moderate-to-severe RA. These findings also indicate that repeated peripheral B cell depletion with rituximab did not give rise to any increased safety risk over time or increased reporting rates of any types of AEs (including infections, cardiovascular events, malignancies or fatal AEs) in the global RA clinical trial programme. Overall, these results are encouraging and should provide clinicians with reassurance regarding the long-term safety of rituximab in RA.

Acknowledgements Support for third-party writing assistance for this manuscript was provided by F Hoffmann-La Roche.

Contributors All authors contributed to the interpretation of the data, drafting and/ or revising the manuscript for intellectual content and approved the final version of the manuscript.

Funding This study and the manuscript preparation were funded by F Hoffmann-La Roche.

Ethics approval The study was conducted in full accordance with the ethical principles of the Declaration of Helsinki or with the laws and regulations of the country in which the research was conducted, whichever afforded greater protection to the individual. The study adhered to the principles outlined in the ICH Guideline for Good Clinical Practice. All participating sites received approval from their institutional review board/Ethics Committee (or equivalent), and all patients provided written informed consent prior to participation in the study.

Competing interests RFvV has received grants, consultancy fees and payments for lectures from Abbott, GSK, MSD, Pfizer, Roche and UCB. PE has received grants from Roche and consultancy fees/honoraria from Pfizer, Merck, Abbot, UCB, Roche and Novartis. COB has received grants and consulting fees/honoraria from Genentech, Roche, Abbott, Amgen, Bristol Myers Squibb, Centocor, Johnson \& Johnson, Janssen, Pfizer and UCB, grants from Biogen Idec, consulting fees from Celgene and Millennium, and royalties from Up-to-Date. EK is a board member of and has received consultancy fees from Abbott, AstraZeneca, Biotest, Bristol Myers Squibb, Centocor, Roche, Genentech, Merck, Nycomed, Pfizer and UCB, has received grants and lecture fees from Abbott, Amgen, Bristol Myers Squibb, Roche, Merck, Pfizer and UCB, grants from AstraZeneca, Centocor, Genzyme and Novartis, and lecture fees from Janssen. RF has received a grant from Metroplex Clinical Research Center, and grants and consultancy from Abbott, Amgen, Jansen, UCB, Pfizer, Bristol Myers Squibb, Roche, Lilly, Sanofi and Merck. DEF has received grants and consulting fees or honoraria from Roche, Genentech and Abbott, grants from Bristol Myers Squibb, consultancy fees and support for travel to meetings from Amgen, UCB and Bristol Myers Squibb, and is a Board member of Arthritis Foundation. NT is an employee of and owns stock in Roche. NC and PBL are both employees of Roche.

Provenance and peer review Not commissioned; externally peer reviewed.

Data sharing statement No additional data are available.

Open Access This is an Open Access article distributed in accordance with the Creative Commons Attribution Non Commercial (CC BY-NC 3.0) license, which permits others to distribute, remix, adapt, build upon this work non-commercially, and license their derivative works on different terms, provided the original work is properly cited and the use is non-commercial. See: http://creativecommons.org/licenses/by-nc/3.0/

\section{REFERENCES}

1. Bongartz T, Sutton AJ, Sweeting MJ, et al. Anti-TNF antibody therapy in rheumatoid arthritis and the risk of serious infections and malignancies: systematic review and meta-analysis of rare harmful effects in randomized controlled trials. JAMA 2006;295:2275-85.

2. Baecklund $\mathbf{E}$, lliadou $A$, Askling J, et al. Association of chronic inflammation, not its treatment, with increased lymphoma risk in rheumatoid arthritis. Arthritis Rheum 2006;54:692-701.

3. Wolfe F, Michaud K. Heart failure in rheumatoid arthritis: rates, predictors, and the effect of anti-tumor necrosis factor therapy. Am J Med 2004;116:305-11.

4. Maini RN, Breedveld FC, Kalden JR, et al. Sustained improvement over two years in physical function, structural damage, and signs and symptoms among patients with rheumatoid arthritis treated with infliximab and methotrexate. Arthritis Rheum 2004;50:1051-65.

5. Genovese MC, Bathon JM, Fleischmann RM, et al. Longterm safety, efficacy, and radiographic outcome with etanercept treatment in patients with early rheumatoid arthritis. J Rheumatol 2005:32:1232-42.

6. Schiff MH, Burmester GR, Kent JM, et al. Safety analyses of adalimumab (HUMIRA $®$ ) in global clinical trials and US postmarketing surveillance of patients with rheumatoid arthritis. Ann Rheum Dis 2006;65:889-94.

7. Askling J, Dixon W. The safety of anti-tumour necrosis factor therapy in rheumatoid arthritis. Curr Opin Rheumatol 2008;20:138-44.

8. Emery P, Deodhar A, Rigby WF, et al. Efficacy and safety of different doses and retreatment of rituximab: a randomised, placebo-controlled trial in patients who are biological naive with active rheumatoid arthritis and an inadequate response to methotrexate (Study Evaluating Rituximab's Efficacy in MTX iNadequate rEsponders (SERENE)). Ann Rheum Dis 2010;69:1629-35.

9. Edwards JC, Szczepañski L, Szechiñski J, et al. Efficacy of B-cell-targeted therapy with rituximab in patients with rheumatoid arthritis. N Engl J Med 2004;350: 2572-81

10. Emery P, Fleischmann R, Filipowicz-Sosnowska A, et al. The efficacy and safety of rituximab in patients with active rheumatoid arthritis despite methotrexate treatment: results of a phase IIB randomized, double-blind, placebo-controlled, dose-ranging trial. Arthritis Rheum 2006;54:1390-400.

11. Cohen SB, Emery P, Greenwald MW, et al. Rituximab for rheumatoid arthritis refractory to anti-tumor necrosis factor therapy: results of a multicenter, randomized, double-blind, placebo-controlled, phase III trial evaluating primary efficacy and safety at twenty-four weeks. Arthritis Rheum 2006;54:2793-806.

12. Keystone $\mathbf{E}$, Fleischmann R, Emery P, et al. Safety and efficacy of additional courses of rituximab in patients with active rheumatoid arthritis: an open-label extension analysis. Arthritis Rheum 2007;56:3896-908.

13. Mease PJ, Cohen S, Gaylis NB, et al. Efficacy and safety of retreatment in patients with rheumatoid arthritis with previous inadequate response to tumor necrosis factor inhibitors: results from the SUNRISE Trial. J Rheumatol 2010:37:917-27.

14. Rubbert-Roth A, Tak PP, Zerbini C, et al. Efficacy and safety of various repeat treatment dosing regimens of rituximab in patients with active rheumatoid arthritis: results of a Phase III randomized study (MIRROR). Rheumatology (Oxford) 2010;49:1683-93.

15. Tak PP, Rigby WF, Rubbert-Roth A, et al. Inhibition of joint damage and improved clinical outcomes with rituximab plus methotrexate in early active rheumatoid arthritis: the IMAGE trial. Ann Rheum Dis 2011;70:39-46.

16. Bingham CO III, Looney RJ, Deodhar A, et al. Immunization responses in rheumatoid arthritis patients treated with rituximab: results from a controlled clinical trial. Arthritis Rheum 2010;62:64-74.

17. van Vollenhoven RF, Emery P, Bingham CO III, et al. Longterm safety of patients receiving rituximab in rheumatoid arthritis clinical trials. J Rheumatol 2010;37:558-67.

18. Centers for Disease Control and Prevention (CDC). Deaths: final data for 2009. 2010;1-90.

19. Fleischmann RM. Progressive multifocal leukoencephalopathy following rituximab treatment in a patient with rheumatoid arthritis. Arthritis Rheum 2009;60:3225-8.

20. Bongartz T, Orenstein R. Therapy: the risk of herpes zoster: another cost of anti-TNF therapy? Nat Rev Rheumatol 2009;5:361-3.

21. Mellemkjaer L, Linet MS, Gridley G, et al. Rheumatoid arthritis and cancer risk. Eur J Cancer 1996;32A:1753-7.

22. Wolfe F, Michaud K. Biologic treatment of rheumatoid arthritis and the risk of malignancy: analyses from a large US observational study. Arthritis Rheum 2007;56:2886-95.

23. National Cancer Institute. Surveillance Epidemiology and End Results database. 2011.

24. Smitten AL, Simon TA, Hochberg MC, et al. A meta-analysis of the incidence of malignancy in adult patients with rheumatoid arthritis. Arthritis Res Ther 2008:10:R45. 
25. Westhovens R, Kremer JM, Moreland LW, et al. Safety and efficacy of the selective costimulation modulator abatacept in patients with rheumatoid arthritis receiving background methotrexate: a 5 -year extended Phase IIB study. J Rheumatol 2009;36:736-42

26. Moreland LW, Weinblatt ME, Keystone EC, et al. Etanercept treatment in adults with established rheumatoid arthritis: 7 years of clinical experience. J Rheumatol 2006;33:854-61.

27. Galloway JB, Hyrich KL, Mercer LK, et al. Anti-TNF therapy is associated with an increased risk of serious infections in patients with rheumatoid arthritis especially in the first 6 months of treatment: updated results from the British Society for Rheumatology Biologics Register with special emphasis on risks in the elderly. Rheumatology (Oxford) 2011:50:124-31.

28. Salliot C, Dougados M, Gossec L. Risk of serious infections during rituximab, abatacept and anakinra treatments for rheumatoid arthritis: meta-analyses of randomised placebo-controlled trials. Ann Rheum Dis 2009;68:25-32.

29. Gottenberg JE, Ravaud P, Bardin T, et al. Risk factors for severe infections in patients with rheumatoid arthritis treated with rituximab in the autoimmunity and rituximab registry. Arthritis Rheum 2010;62:2625-32.
30. Lee ML, Gale RP, Yap PL. Use of intravenous immunoglobulin to prevent or treat infections in persons with immune deficiency. Annu Rev Med 1997;48:93-102.

31. Solomon DH, Goodson NJ, Katz JN, et al. Patterns of cardiovascular risk in rheumatoid arthritis. Ann Rheum Dis 2006;65:1608-12.

32. Gabriel SE. Cardiovascular morbidity and mortality in rheumatoid arthritis. Am J Med 2008;121:S9-14.

33. Dixon WG, Watson KD, Lunt $\mathrm{M}$, et al. Reduction in the incidence of myocardial infarction in patients with rheumatoid arthritis who respond to anti-tumor necrosis factor alpha therapy: results from the British Society for Rheumatology Biologics Register. Arthritis Rheum 2007:56:2905-12.

34. Watson DJ, Rhodes T, Guess HA. All-cause mortality and vascular events among patients with rheumatoid arthritis, osteoarthritis, or no arthritis in the UK General Practice Research Database. J Rheumatol 2003;30:1196-202.

35. Slimani S, Lukas C, Combe B, et al. Rituximab in rheumatoid arthritis and the risk of malignancies: report from a French cohort. Joint Bone Spine 2011;78:484-7.

36. Jacobsson LT, Turesson C, Nilsson JA, et al. Treatment with TNF blockers and mortality risk in patients with rheumatoid arthritis. Ann Rheum Dis 2007;66:670-5. 